\title{
Estimation of the Impact of the Forces from an External Explosion to Building Faces on the Responses of a 3D Frame Structure
}

\author{
Farzad Sadeghi, ${ }^{1}$ Seyyed Reza Sarafrazi, ${ }^{2}$ and Ali Ghods ${ }^{1}$ \\ ${ }^{1}$ Department of Civil Engineering, Islamic Azad University, Zahedan Branch, Zahedan 98138-987, Iran \\ ${ }^{2}$ Department of Civil Engineering, Birjand University, Birjand 97175-615, Iran
}

Correspondence should be addressed to Farzad Sadeghi; farzad_ict@yahoo.com

Received 21 January 2014; Accepted 4 March 2014; Published 31 March 2014

Academic Editors: X. Li and J. Wang

Copyright (C) 2014 Farzad Sadeghi et al. This is an open access article distributed under the Creative Commons Attribution License, which permits unrestricted use, distribution, and reproduction in any medium, provided the original work is properly cited.

\begin{abstract}
Surface explosions resulting from terrorist attacks will produce a hemispherical shock wave in the air, which, upon release, can affect five faces of the building which is in front of it. Given the fact that conventional buildings are usually exposed to such explosions, this study examined the effect of pressure to each face of a building on the responses of the structure and has compared different relevant scenarios. This study, which includes the following two steps, was conducted as a case study on earthquake resistant RC buildings, with the help of UFC guideline and using the software SAP2000. In the first step, responses of loading on each face were separately calculated so that they were compared with the responses from overall loading on all faces. The sensitivity of the responses and their ratio to the variables considered were evaluated in the second step. Accordingly, an outline was formed on the explosion hazards considered for these types of buildings.
\end{abstract}

\section{Introduction}

Following the increased terrorist attacks in the past decade and consequently many human and financial losses to the international community, extensive studies are underway on the phenomenon. Structural engineering is a field that has entered into this arena to reduce losses and examine the nature of the phenomenon and its effects on buildings where people gather and are the target of such attacks. In addition to these studies, some researches have been conducted on issues related to nonterrorist and accidental explosions as well as side phenomena of explosion.

In studies close to the subject of our research, which were conducted in recent years to evaluate the vulnerability and damage to an RC frame building affected by the explosion, it was found that a combination of global and local analyses are needed to evaluate the effect of explosions on structures; the former to determine the critical and more damaged members and the latter to evaluate the extent of damage and the behavior of members [1]. In addition, a study about the effect of seismic design on the behavior of an RC frame building against internal and external explosions showed that, although seismic criteria do not provide sufficient structural robustness against blast scenarios, they cause more strength and less displacement in the building [2]. The results of a study focused on the residual strength of RC building columns which show that the use of seismic design can significantly reduce the extent of direct damage from the explosion and subsequent collapse [3]. Another study on concrete buildings also indicates that a more realistic assessment about the impact of explosion on structures can be achieved when the analytical model of a building is updated on the basis of Operational Modal Analysis (OMA) results and when the dynamic analysis is carried out for the blast record [4]. Other recent studies examine the impact of ground motions caused by the shock of the explosion and its comparison with the effects of earthquakes on rigid building blocks, the effect of shear wall on RC buildings retaining turbines in the nuclear industry, and the exact simplification of the time history of blast pressure; and other study have developed a method to calculate the annual collapse risk in strategic buildings [5-8]. 
Most of these studies, which have been conducted on the explosion-targeted buildings, have mainly focused on the positive phase of the direct explosion force applied to the front face of the building so that the effects of pressures on other faces and the negative phase (i.e., the suction force of the explosion) are ignored. But in the vicinity of the target buildings, there are other buildings farther from the explosion, which cannot be locally affected by an explosion that has an integrated effect on the building. The authors of this paper have determined the amount of the effect of pressure to each face of a building has on the structure responses, by examining the far blast modes that have nonlocal effects on the building, as follows. Responses to pressure on each face of the building have been separately calculated by taking into account the positive and negative phase of blast, which were compared with the responses caused by the simultaneous effect of explosion on all the faces. Then, sensitivities of the single and overall responses and their ratio to the variables considered were evaluated. To this end, the UFC guideline was used to calculate the pressure-time diagrams of the explosion on each side of the building [9] and the software SAP2000 was used for modeling. Furthermore, the intended explosions are of the external surface blast type with solid explosives.

\section{Modeling}

This research was conducted as a case study on three RC moment frame buildings. The buildings were designed as earthquake resistant, based on the current codes. Furthermore, the buildings are regular in plan and elevation and have three spans of 5 meters in each direction, with the height of 4,6 , or 8 floors. Dead and live floor loads (DL and LL) as well as specified concrete compressive strength $\left(f_{c}^{\prime}\right)$ are equal to $600 \mathrm{Kg} / \mathrm{m}^{2}, 200 \mathrm{Kg} / \mathrm{m}^{2}$, and $280 \mathrm{Kg} / \mathrm{cm}^{2}$, respectively, and the height of each story is considered equal to 3 meters.

A linear modal analysis was taken into account for the dynamic analysis of this study. To this end, the explosive charge weight and distance were determined to create an integrated and nonlocal effect on the structure and not enter the structure in a nonlinear phase. Accordingly, four blast modes were determined according to Table 1 , wherein the scaled distance factor $Z$ will be approximately equal for the explosions 1 and 2 and the explosions 3 and 4 , given that the explosions are in far blast areas [9].

Consider

$$
Z=\frac{R}{\sqrt[3]{W}}
$$

where $R$ and $W$ are the distance from the blast site and the explosive charge weight, respectively.

The pressure-time diagrams for all faces of the buildings were calculated using the UFC 3-340-02 (2008) guideline [9]. An example of these diagrams is given in Figures 1, 2, 3, and 4 for the explosion 1 . Then, the buildings were modeled in the software SAP2000, and the pressure-time diagrams were applied as time history functions to the building faces. Accordingly, three buildings were subjected to four explosive
TABLE 1: Charge weight and distance for the intended explosions.

\begin{tabular}{lccc}
\hline Number & Charge weight $(\mathrm{kg})$ & Distance $(\mathrm{m})$ & Scaled distance \\
\hline Explosion 1 & 2000 & 50 & 3.97 \\
Explosion 2 & 6750 & 75 & 3.97 \\
Explosion 3 & 600 & 50 & 5.95 \\
Explosion 4 & 2000 & 75 & 5.95 \\
\hline
\end{tabular}

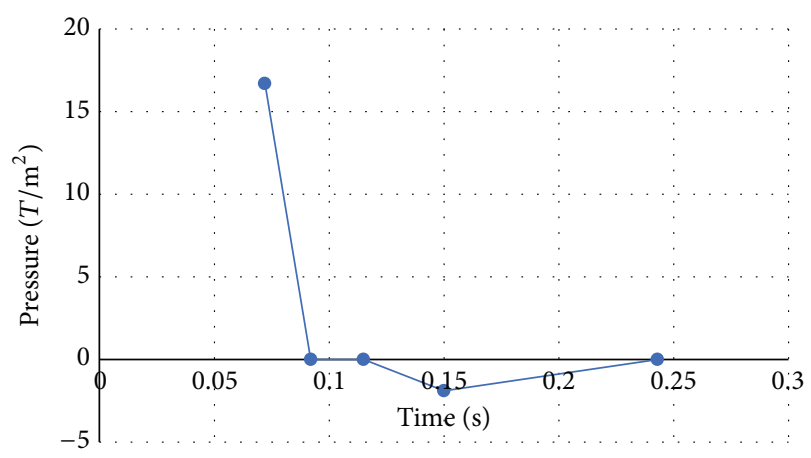

FIGURE 1: Pressure-time diagram for front face.

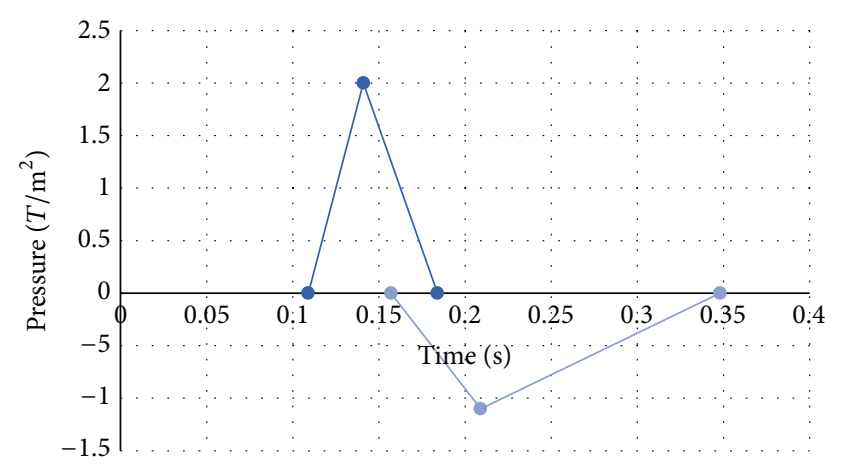

FIGURE 2: Pressure-time diagram for back face.

modes, which included a total of 12 samples. Given the study is focused on a comparison between the responses of loading of each face and overall loading, blast forces in the modeling were applied to the junctions of beams and columns in each face. Consequently, the effect of the construction material type for infills as well as the air entry into the building and its secondary effects were ignored. The forces on the roof, of course, were applied to the beams due to the rigid diaphragm.

\section{Evaluation of Results}

In this study, the parameters of displacement, shear, moment, and axial force of the floors were selected as criteria to evaluate. Furthermore, the explosive charge weight, explosive distance, scaled distance, and building height were considered as variable parameters. Accordingly, in the first phase of the study, blast loading was performed for all faces of the building, and the generated responses were recorded as overall responses. After loading was done separately for each 


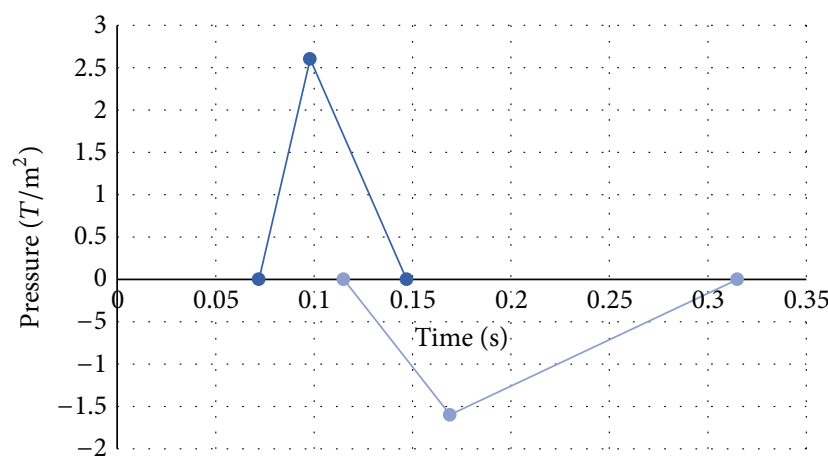

FIgURE 3: Pressure-time diagram for roof face.

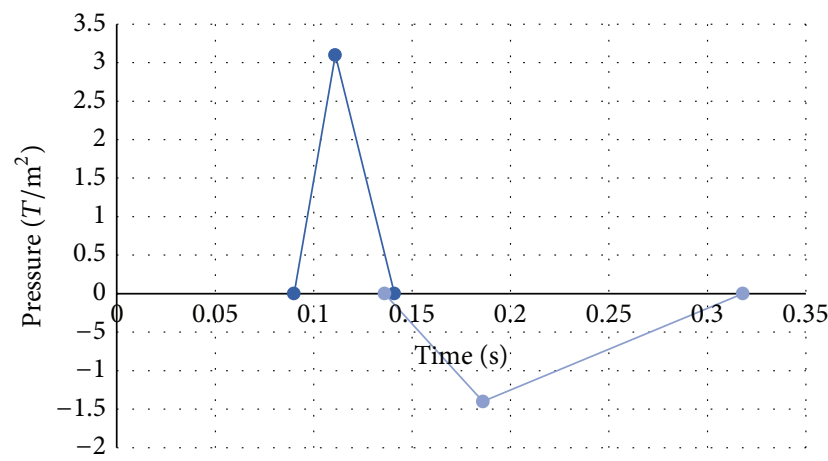

FIGURE 4: Pressure-time diagram for side faces.

face, the resulting responses were compared with the overall responses. In the second phase, the sensitivity of responses and their ratio to the variables were evaluated.

3.1. First Phase. The results of the first phase showed that the shear resulting from the front load $\left(V_{x}\right)$ in the direction of the blast was between 90 and 115 percent of shear in the overall case. The moment resulting from the front load $\left(M_{y}\right)$ was between 85 and 135 percent of the overall moment, and roof displacement from the front load $\left(U_{x}\right)$ was between 120 and 140 percent in the overall case. For back loads, the ratios were estimated at $20-70$ percent, $30-80$ percent, and 20-90 percent, respectively. Accordingly, the back force has a decreasing role in the displacement of floors and for the 12 samples under study, the mean displacement from front force was $25 \%$ higher than the displacement caused by the combination of the overall load on the upper level of the building. However, in all 8 samples ( 6 and 8 story buildings), the base shear due to pressure of front face was equal to the base shear created in the overall loading, and the above variations in the ratios were seen in the four-story buildings. The story displacement and shear in the direction of the blast for one of the samples can be seen in Figures 5 and 6 .

The values and the ratio between the responses of individual and overall loads are shown in Table 2, which is related to the six-story building under the explosion 1 .

In this table, the ratio of each response has been measured to the overall response of the same column or its left column (the bold values are the base responses to measure the ratios).

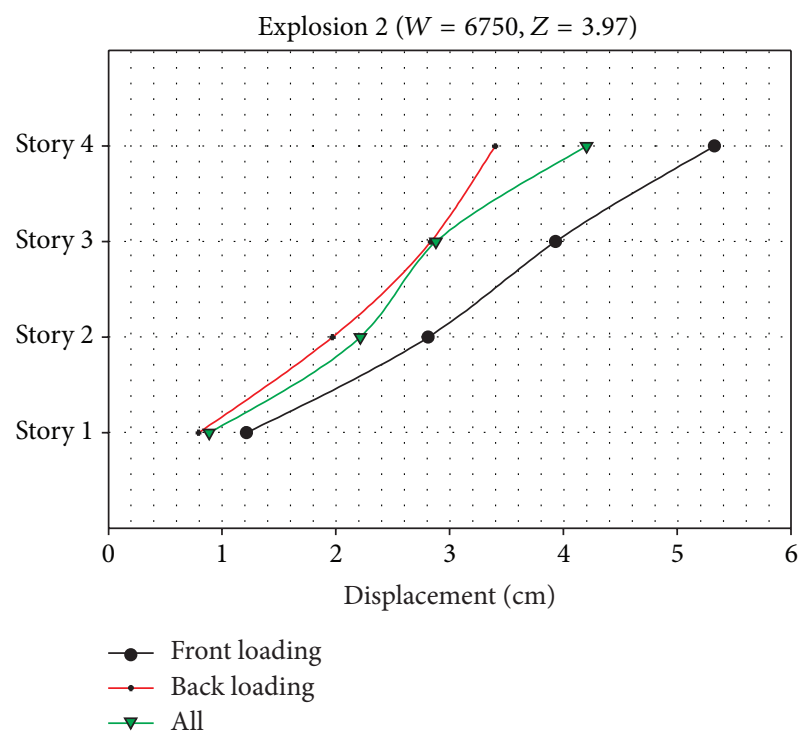

FIGURE 5: Displacement of four-story building.

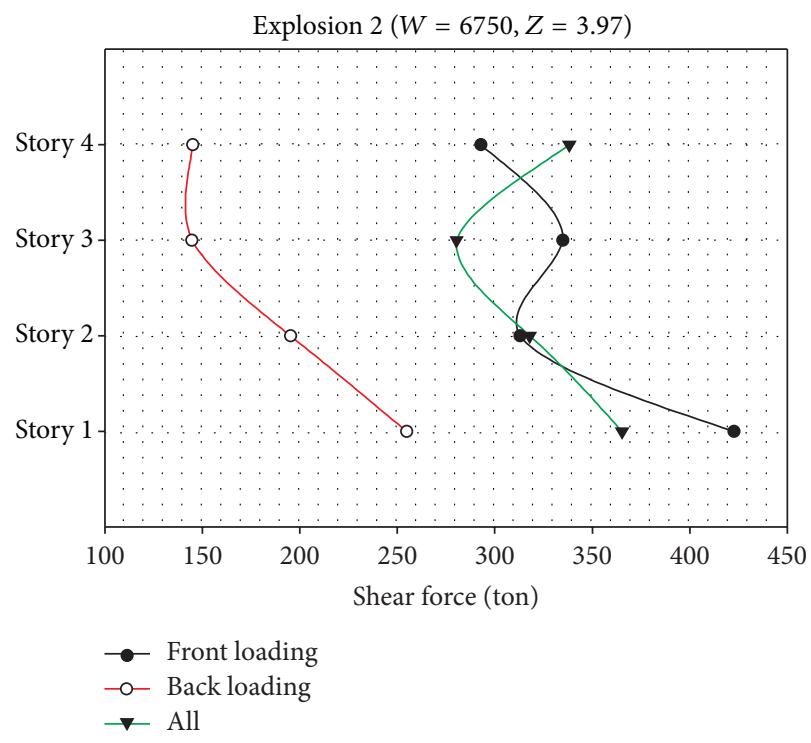

FIGURE 6: Shear of four-story building.

In this table, the resultant of axial force $\left(F_{z}\right)$ is equal to zero for horizontal loads, but the force of half of the columns under pressure or tension is included for better understanding.

In the direction perpendicular to the blast direction of the force of lateral faces, the effects offset each other due to the symmetry of the building and generally create no response in structure. Hence, the ratio of responses of a single loading to those of overall loading in the direction of the blast was evaluated in this paper, in order to compare them. Accordingly, the shear resulting from the lateral force $\left(V_{y}\right)$ was determined to be $40-80$ percent of shear in the overall case, the moment resulting from the lateral force $\left(M_{x}\right)$ to be 45-95 percent of overall moment, and the roof displacement resulting from the lateral force $\left(U_{y}\right)$ to be $30-135$ percent of the overall displacement. 
TABLE 2: The ratio between the responses of individual and overall loads.

\begin{tabular}{|c|c|c|c|c|c|c|c|c|c|}
\hline & & \multicolumn{3}{|c|}{ Base reaction (ton) } & \multicolumn{2}{|c|}{ Base moment (ton·m) } & \multicolumn{3}{|c|}{ Roof displacement $(\mathrm{cm})$} \\
\hline & & $V_{x}$ & $V_{y}$ & $F_{z}$ & $M_{y}$ & $M_{x}$ & $U_{x}$ & $U_{y}$ & $U_{z}$ \\
\hline \multirow{2}{*}{ Front } & Amount & 287.99 & 0 & 105 & 582.06 & 0 & 3.97 & 0 & 0.05 \\
\hline & Ratio (\%) & 100 & 0 & 36.46 & 100 & 0 & 129.62 & 0 & 25.93 \\
\hline \multirow{2}{*}{ Back } & Amount & 119.89 & 0 & 46.94 & 320.15 & 0 & 1.88 & 0 & 0.02 \\
\hline & Ratio (\%) & 41.63 & 0 & 16.3 & 55 & 0 & 61.27 & 0 & 10.8 \\
\hline \multirow{2}{*}{ Right } & Amount & 0 & 168.6 & 70.3 & 0 & 446.14 & 0 & 2.81 & 0.03 \\
\hline & Ratio (\%) & 0 & 58.54 & 24.41 & 0 & 76.65 & 0 & 91.93 & 16 \\
\hline \multirow{2}{*}{ Left } & Amount & 0 & 168.6 & 70.3 & 0 & 446.14 & 0 & 2.81 & 0.03 \\
\hline & Ratio (\%) & 0 & 58.54 & 24.41 & 0 & 76.65 & 0 & 91.93 & 16 \\
\hline \multirow{2}{*}{ Roof } & Amount & 0.46 & 0.46 & 1053.94 & 0.94 & 0.94 & 0 & 0 & 0.19 \\
\hline & Ratio (\%) & 0.16 & 0.16 & 365.96 & 0.16 & 0.16 & 0 & 0 & 99.64 \\
\hline \multirow{2}{*}{ Overall } & Amount & 287.99 & 0.46 & 1057.82 & 582.06 & 0.94 & 3.06 & 0 & 0.19 \\
\hline & Ratio (\%) & 100 & 0.16 & 367.31 & 100 & 0.16 & 100 & 0 & 100 \\
\hline
\end{tabular}

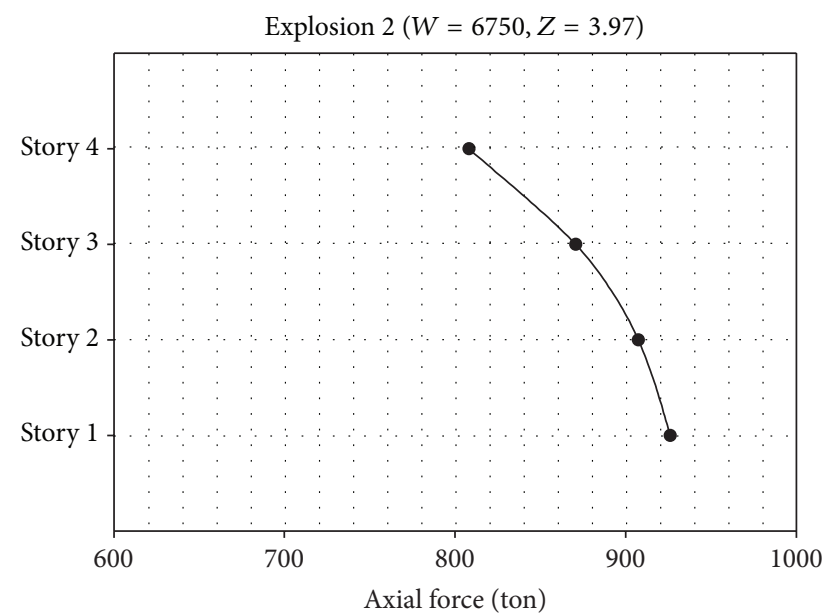

FIgURE 7: Axial force of 4-storey building.

However, the most significant result was related to the vertical force $\left(F_{z}\right)$ caused by pressure on the roof. This force is particularly a function of the roof load and is $2.5-4.5$ times the overall shear in size, in the direction of the blast $\left(V_{x}\right)$. In all cases, the ratio of the above force to the force due to the weight of the building was found to be much greater in the upper floors. For example, given that the weight of each floor is approximately $220 \mathrm{~kg}$, the vertical force on the upper floor is nearly four times the weight of the floor in size, in the samples visible in (Figure 7) and is slightly more than the building weight at the base of the building.

3.2. Second Phase. In the second phase of the study, the sensitivity of responses obtained and their ratios to the considered variables were evaluated. Accordingly, the main observations are as follows.
3.2.1. The Same Scaled Distance. Although the peak reflective pressure generated is equal in two modes with the same scaled distance, the duration of the effect is higher in more away blasts, which is expected to generate a greater response in the structure. The results of the study showed that in the overall loading, if the scaled distance is kept constant and the charge weight and distance can rise by half and more than 3 times, respectively, then the base shear and moment in the direction of the blast $\left(V_{x}\right.$ and $\left.M_{y}\right)$, on average, can increase by 40 percent (with some fluctuation in the models) for the overall loading. However, the vertical force $\left(F_{z}\right)$ indicated an increase of 3-15 percent in the overall case, and its ratio to basic shear was reduced. In single loads, the ratio of shear, moment, and displacement resulting from the rear and lateral loads to base responses increased with distance.

3.2.2. The Same Distance. In the bursts under study, pressures from the explosion on building surfaces increased more than twice the weight of the explosive charge, assuming a constant distance. In this case, all overall responses almost increased by the same proportion. However, the responses of the rear and lateral loads had more growth so that they showed a growth of 2.5 to 4.5 times in the different samples, and the ratio of shear, moment, and displacement resulting from them to the base responses increased with the charge weight.

3.2.3. The Same Charge Weight. In the case where the distance from a $2000 \mathrm{~kg}$ explosive decreased by 30 percent from the explosion 1 through the explosion 4 , the pressure on the building faces increased more than twice. In this case, maximum reaction was observed in the overall vertical force $\left(F_{z}\right)$ that increased by two times. Its corresponding displacement $\left(U_{z}\right)$ also showed an increase of less than 2 times. Different samples increased by $50-70 \%$ in the overall shear $\left(V_{x}\right), 40-60 \%$ in the overall moment $\left(M_{y}\right)$, and $20-35 \%$ in its corresponding displacement $\left(U_{x}\right)$. 


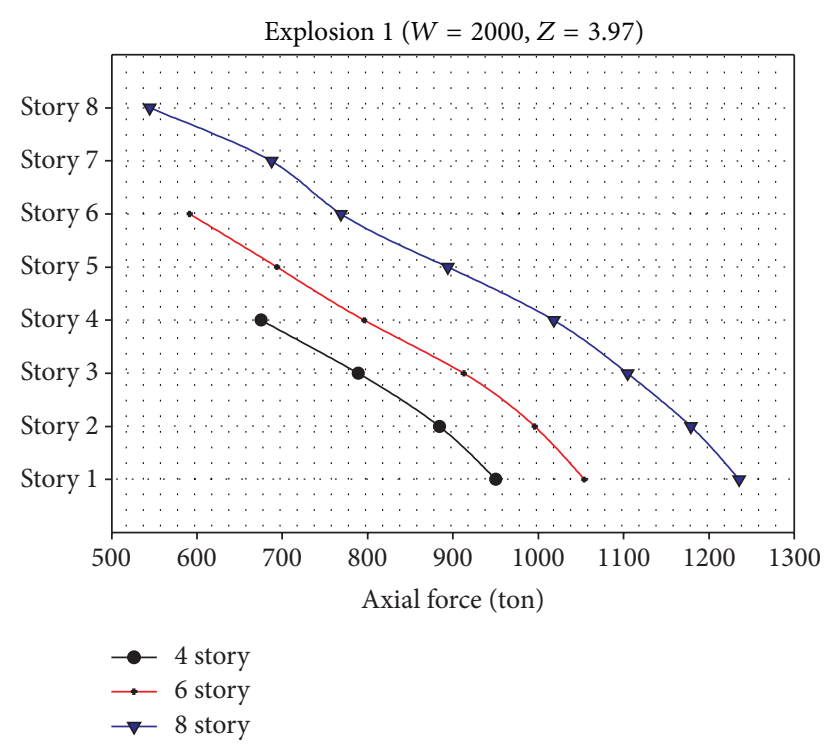

FIgURE 8: Axial forces from roof load.

3.2.4. The Same Explosion. Considering that the explosions under study are not in the near blast areas, no significant changes are found in the pressure-time diagrams, assuming a constant explosion and a change in building height. Evaluation of the responses indicated that maximum effect was observed in the overall vertical displacement of the roof $\left(U_{z}\right)$, which on average increased by two times, while the corresponding force $\left(F_{z}\right)$ in the general case showed an increase of 35-60 percent in different models (Figure 8).

\section{Conclusions}

This study was aimed at examining the effect of an external explosion on conventional earthquake-resistant buildings, to explain the degree of building response to each of the forces on its faces. The study results could help to provide engineers with an overview to identify the type and extent of the vulnerability of buildings in seismic areas against explosion, which can also contribute to the discussion on strengthening the buildings. Based on the results, the major findings of this study can be summarized as follows.

(i) Despite the lower peak pressures, the forces on the side, back, and roof surfaces of the building alone create significant structural responses.

(ii) The axial force on the structure, in particular, is a function of the roof load and is a large quantity, compared with other forces. As a result, its effect on the roof and the $P-\Delta$ effect in columns should be considered.

(iii) The ratio of the axial force due to the pressure of building roof to the axial force due to the weight of the building is significantly higher in the upper floors. In all the floors, the ratio decreases with the height of the building. (iv) In most cases, the contribution of rear load either leads to a decreased response in the direction of the blast or has no effect on them, except in rare cases where it leads to a low increase of some responses.

\section{Conflict of Interests}

The authors declare that there is no conflict of interests regarding the publication of this paper.

\section{References}

[1] R. Jayasooriya, D. P. Thambiratnam, N. J. Perera, and V. Kosse, "Blast and residual capacity analysis of reinforced concrete framed buildings," Engineering Structures, vol. 33, no. 12, pp. 3483-3495, 2011.

[2] F. Parisi and N. Augenti, "Influence of seismic design criteria on blast resistance of RC framed buildings: A Case Study," Engineering Structures, vol. 44, pp. 78-93, 2012.

[3] X. Bao and B. Li, "Residual strength of blast damaged reinforced concrete columns," International Journal of Impact Engineering, vol. 37, no. 3, pp. 295-308, 2010.

[4] A. Bayraktar, T. Türker, A. C. Altunişik, and B. Sevim, "Evaluation of blast effects on reinforced concrete buildings considering Operational Modal Analysis results," Soil Dynamics and Earthquake Engineering, vol. 30, no. 5, pp. 310-319, 2010.

[5] H. Hao and Y. Zhou, "Rigid structure response analysis to seismic and blast induced ground motions," Procedia Engineering, vol. 14, pp. 946-955, 2011.

[6] D. Asprone, F. Jalayer, A. Prota, and G. Manfredi, "Proposal of a probabilistic model for multi-hazard risk assessment of structures in seismic zones subjected to blast for the limit state of collapse," Structural Safety, vol. 32, no. 1, pp. 25-34, 2010.

[7] B. Li, T.-C. Pan, and A. Nair, "A case study of the effect of cladding panels on the response of reinforced concrete frames subjected to distant blast loadings," Nuclear Engineering and Design, vol. 239, no. 3, pp. 455-469, 2009.

[8] J. Dragos, C. Wu, and D. J. Oehlers, "Simplification of fully confined blasts for structural response analysis," Engineering Structures, vol. 56, pp. 312-326, 2013.

[9] Unified Facilities Criteria, UFC3-340-2: Structures to Resist the Effects of Accidental Explosions, USA Department of Defens, Washington, DC, USA, 2008. 

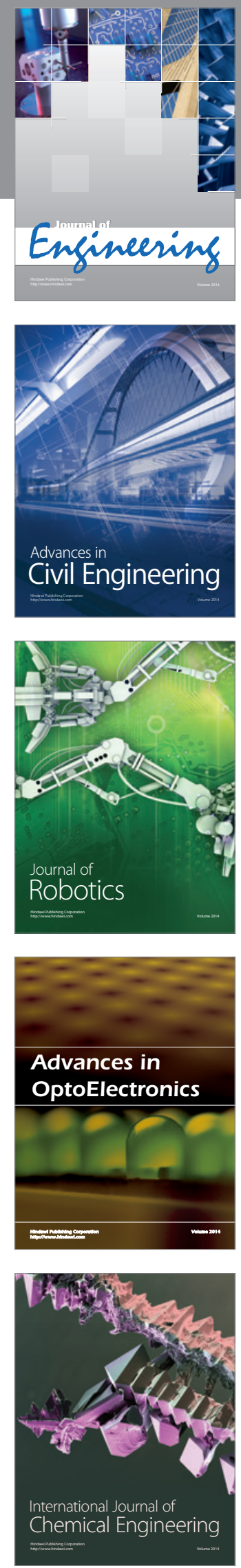

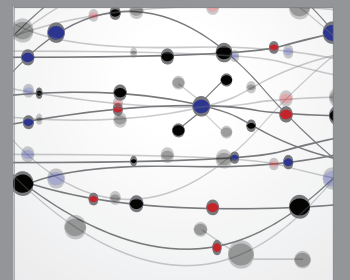

The Scientific World Journal
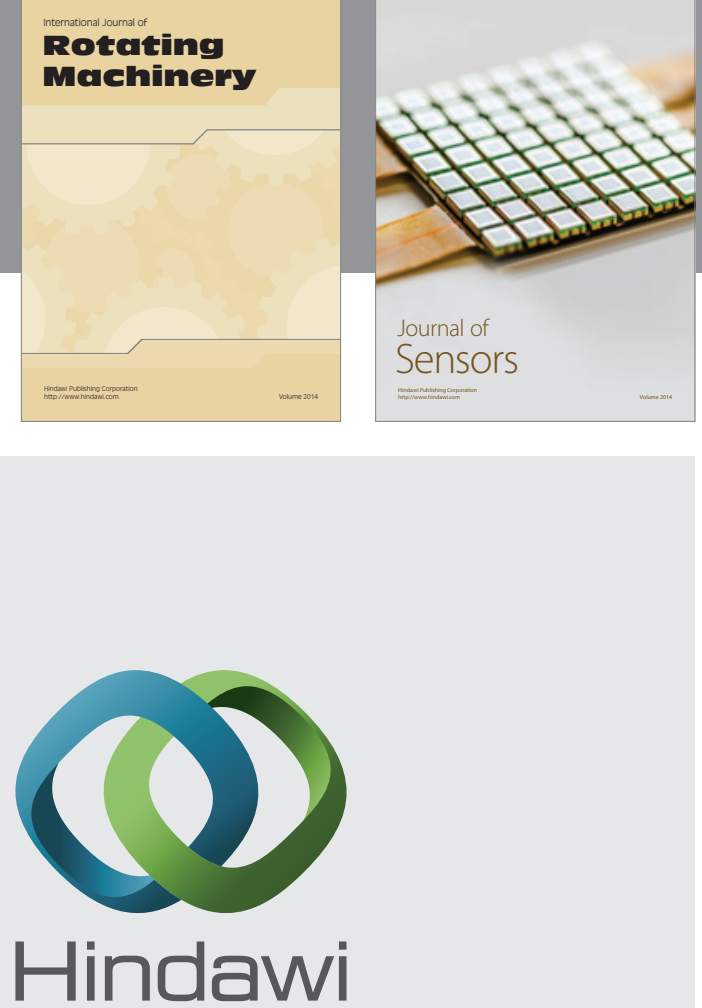

Submit your manuscripts at http://www.hindawi.com
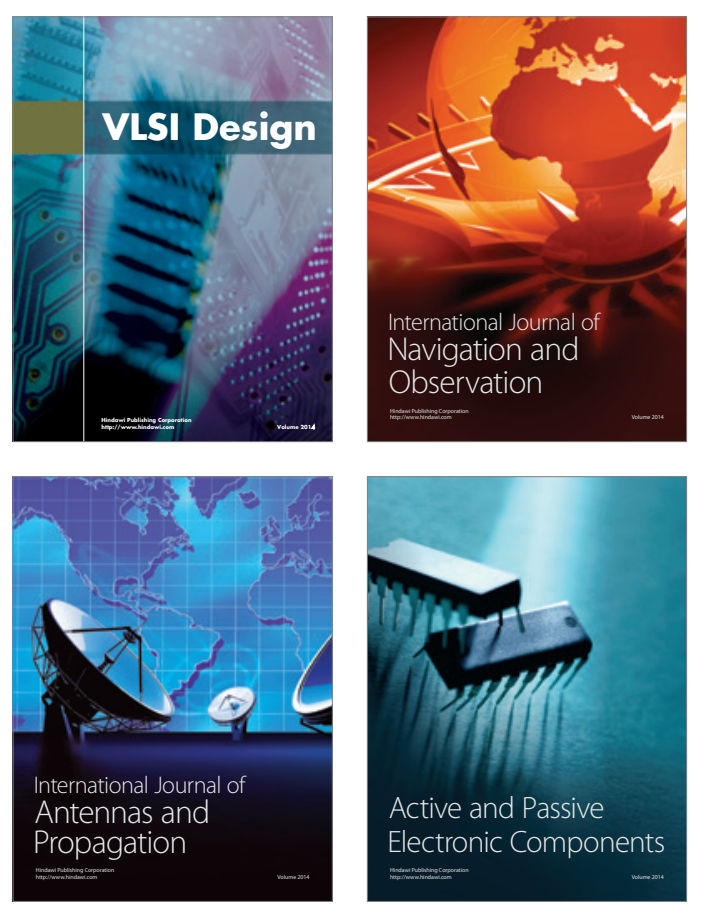
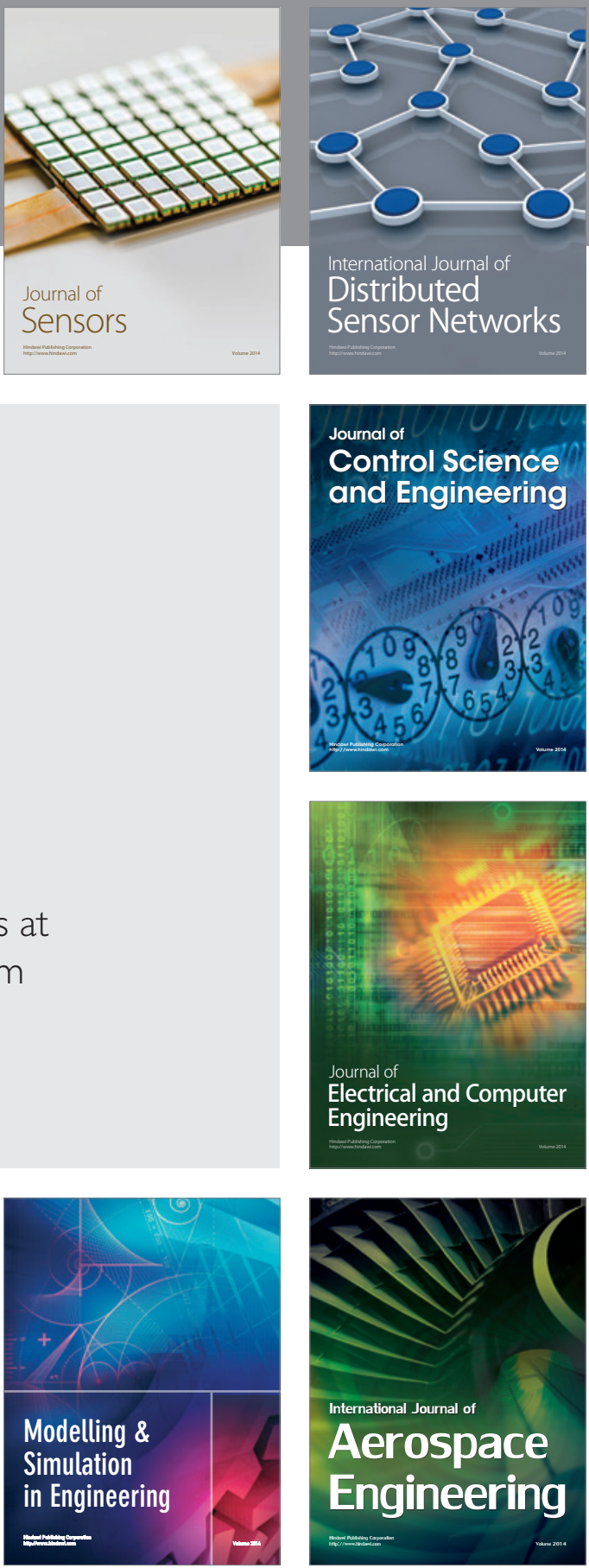

Journal of

Control Science

and Engineering
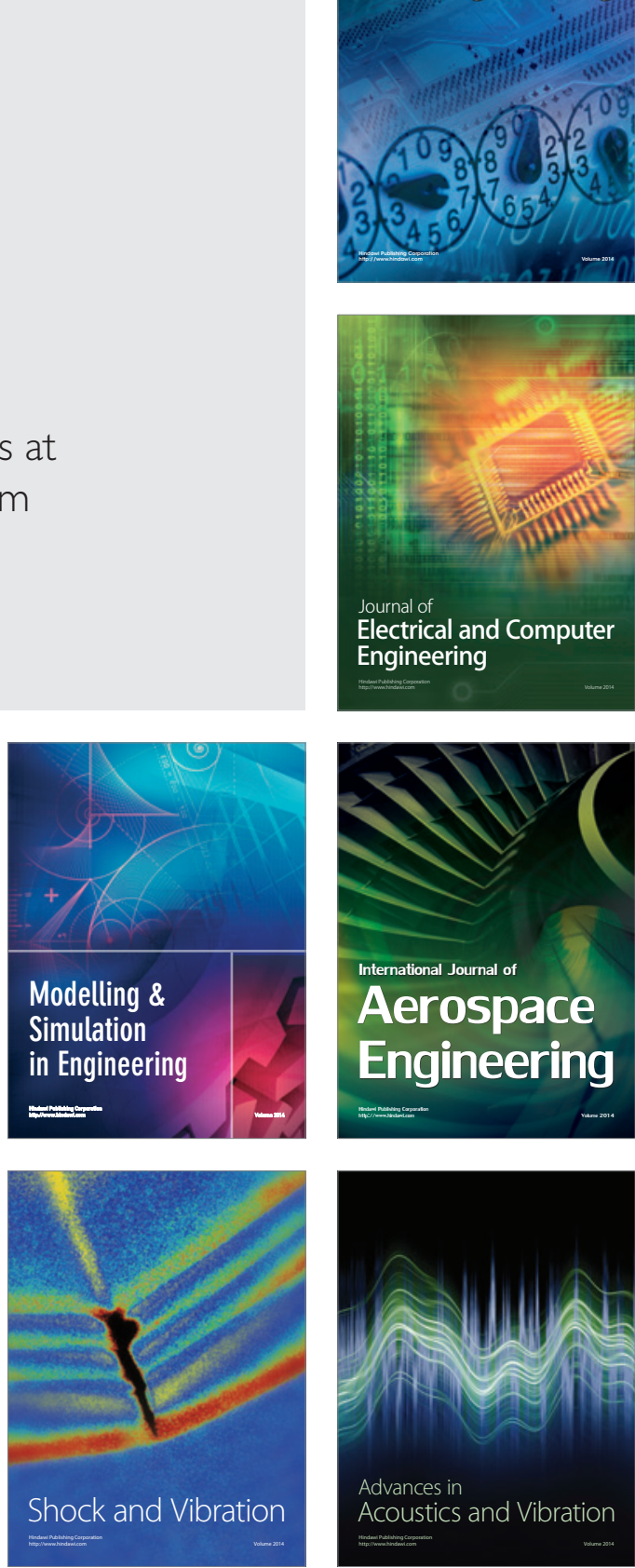